logically as the periosteum of the alveolus; and further, that the tissue is a continuation of the periosteum.

In the next picture (Fig. 8) is shown a field which presents the future neck of the permanent tooth and also its gingivus. At 1 we note the area occupied by the enamel; 2 is the future gingivus and point of attachment to the periosteum ; 3 is the dentine; 4 is the alveolar dental ligament, 5 is the alveolar border of the alveolus.

In the next picture (Fig. 9) is shown a higher magnification of the same field as shown in Fig. 8. At 1 is shown the future gingival attachment of the periosteum; at 2 is shown the cementum, and directly to the left of the heavy shaded cementum, some cemental cells are shown. This row of cells can be traced by careful focusing to the extreme apical area of the developing tooth. At 3 is shown the alveolar border; at 4 , the future alveolar dental ligament.

From the foregoing pictures we learn that the alveolar dental ligament of the tooth and the periosteum of the alveolus are histologically the same in type; and that the alveolar dental ligament is a direct continuation of the periosteum into the root socket; and, further, that the fibrous capsule which surrounds the developing permanent tooth is a direct continuation of the alveolar dental ligament of the deciduous tooth, and, therefore, the fibrous capsule is a continuation of the periosteum. We also learn that the function of the alvcolar dental ligament is that of a ligament, also that it is a limiting membrane, and that it is not concerned in the development of the cementum or the alveolus directly. But, as previously stated, it limits the growth of the cementum of the root of the tooth and the alveolus that forms the root socket.

\title{
TREATMENT OF A CASE OF EXTREME MAXILLARY MALFORMATION IN ADULT LIFE
}

\author{
By L. J. Huber, D.D.S., St. GeNevieve, Mo.
}

$\mathrm{F}$

IGURE 1 represents the unfortunate condition of a lady who was permitted to reach adult life with an extreme type of maxillary malformation and labioversion of the upper incisors. This condition seriously impaired the normal masticatory function in its initial stage and resulted in a repulsive type of facial deformity, with the central incisors exposed and a marked eversion of the lips.

Properly administered orthodontic treatment in her youth, would have arrested the malformation and corrected the malocclusion and the accompanying facial deformity. In reply to her repeated inquiries, the presumably authoritative, though unscrupulous, advice was, that she would outgrow her deformity in a few years. In this instance the patient had to learn through bitter experience, as many others have, the truth of the statement that, "Malocclusion and its accompanying deformities grow steadily worse; nature and time rarely exercise a corrective influence," as Lischer points out in his admirable book, "Orthodontics." 
The patient in her 28th year, painfully conscious of her malocclusion and facial deformity, applied to the writer for treatment. Aiter a cousideration of the nature and extent of the abnormality to be corrected, and the combition to be established, it was evident that any effort to bring about the desired re sult by orthodontic treatment would prove iutile. However, the possilitity of surgical means as an effective procedure suggested itself.

Following the administration of a local anesthetic, the upper central and lateral incisors were extracted, the overlying soft tisstes with the frefiostetm dissected back about, $10 \mathrm{~mm}$. of the labial and about $8 \mathrm{~mm}$. of the lingual process curetted off, thus presenting a rounded surface. Vext the interproximal points of gum tissue were clipped off allowing the tissue to meet in apposition.

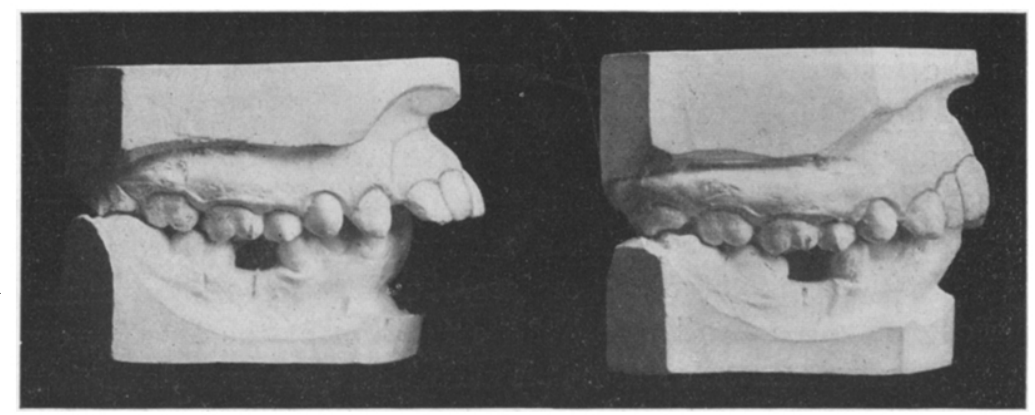

Fig. 1 .

Fig. $\because$

Surgical stitches were employed for the purpose of lolding the tissues in position; these were removed after four days.

After a period of three weeks, conditions were such as to permit the inser tion of a four tooth individual saddle bridgc with inlay attachments to the cuspid teeth. The results obtained can be seen in Figure 2, a marked reduc tion of the labial arch; not a normal, but a vastly ameliorated occlusion. The patient can now bite off foorls; upon closure of the jaws, the lips meet in apposition, and a marked degree of improvement is noticeable in the profile.

One year has elapsed since the above operation was performed, and in that time the patient has twice reported for observation of conditions. The results obtained are permanent and satisfactory in every respect; and in my opinion, this is the proper method of treatment for such conditions in adult life. 